\title{
Reconsidering cell-assisted lipotransfer for breast augmentation: effect of stromal vascular fraction enrichment on graft survival assessed with 3-dimensional laser scanning
}

\author{
Li-Chen Chiu', Li-Shu Chiu', Cheng-Hung Chiu, MD \\ ${ }^{1}$ College of Medicine, Taipei Medical University, Taipei City, Taiwan, ${ }^{2} \mathrm{Fu}$ Jen Catholic University, New Taipei City, Taiwan, ${ }^{3}$ Division of Aesthetic \\ Medicine \& Cosmetic Surgery, Genesis Group-Practice Clinic, Taipei City, Taiwan
}

Background: Cell-assisted lipotransfer (CAL) has been proposed to be beneficial for improving graft retention. Clinically, CAL involves the isolation of the stromal vascular fraction (SVF) from a portion of the lipoaspirate at the time of surgery. However, most studies related to SVF breast augmentation lacked a rigorous methodology and well-designed control.

Objective: We aimed to determine the potential improvement of SVF enrichment in fat grafting for breast augmentation with objective volume assessment.

Methods: From April 2015 to January 2016, 169 patients were enrolled after applying the exclusion criteria. Among them, 97 patients who underwent conventional fat grafting for breast augmentation were assigned to group A. The other 72 patients underwent SVFenriched fat grafting for breast augmentation and were assigned to group B. A retrospective comparative study was conducted to evaluate the graft survival using 3 -dimensional laser scanning.

Results: There was no significant difference between the 2 groups in terms of mean age, original breast volume, grafted fat volume, and postoperative weight change. Breast volume assessments revealed that the percentage of graft survival at 12 months was $69.2 \%$ in group $A$ and $71.1 \%$ in group $B$, with no significant difference $(p=0.641)$. The preoperative body mass index was significantly lower in group A than in group B. The volume of suctioned fat was significantly less in group A. The operation time was significantly shorter in group $A$. The postoperative complication rates were significantly lower in group A than in group B.

Conclusion: SVF-enriched fat grafting for breast augmentation was associated with a larger amount of harvested fat, a longer operation time, and a higher incidence of complications. The graft retention rate was not significantly increased. The findings of our study do not support the use of SVF in fat grafting for breast augmentation.

Level of Evidence: IV

Keywords: adipose-derived stem cells; autologous fat grafting; breast augmentation; cell-assisted lipotransfer; 3-dimensional laser scanning; stromal vascular fraction 


\section{Introduction}

Cell-assisted lipotransfer (CAL) has been proposed to be beneficial for improving graft retention in reconstructive and cosmetic surgeries [1-3]. Isolated mesenchymal stem cells from adipose tissue demonstrate the potential to differentiate into mesenchymal, including adipogenic, lineages [4]. Considering the ease of isolation and abundant supply, isolation and supplementation of adipose-derived regenerative cells during fat grafting surgery has become attractive $[5,6]$.

Studies have revealed that harvesting fat grafts through liposuction reduces the amount of adipose-derived stem cells (ADSCs) $[7,8]$. This opens room for supplementation of the lipoaspirate with stromal cells and stem cells isolated from another portion of fat tissue during conventional liposuction. Supplementation aims to restore the amount of ADSCs in the graft to approach the amount seen in native adipose tissue. The isolation procedure of adipose tissue creates a stromal vascular fraction (SVF) layer that is composed of a host of cells, including stem cells and others $[9,10]$. However, most of the published studies with respect to SVF supplementation for breast augmentation are short of a rigorous methodology. Further, the absence of a control group in most of the previous studies makes it difficult to confirm the efficacy of CAL. The current level of evidence surrounding CAL does not allow drawing a solid conclusion about its use in the clinical setting [11-13].

Magnetic resonance imaging (MRI) and 3-dimensional (3D) imaging both provide accuracy and reliability in breast volume measurement $[14,15]$. MRI is known for its precision in estimating breast volume and detecting internal consistency. However, for frequent postoperative follow-up, repeated MRI examinations would not be practical or cost-effective. Threedimensional surface imaging, including $3 \mathrm{D}$ laser scanning, is a better option in these cases $[16,17]$.

We aimed to determine the potential benefit of SVF enrichment in fat grafting for breast augmentation with objective assessment using 3D laser scanning. A retrospective comparative study was conducted to evaluate the change of breast volume in consecutive patients who underwent conventional fat grafting and those who underwent SVF-enriched fat grafting for breast augmentation.

\section{Materials and methods}

This retrospective study was approved by the Institutional Review Board of the Genesis Group-Practice Clinic and was conducted in compliance with the STROBE (STrengthening the Reporting of OBservational studies in Epidemiology) guidelines [18]. Informed consent was obtained from all patients, who had been informed of the potential adverse events after surgery. In addition, each patient's written consent was obtained for publication. At the time of the study, the surgeon ( $\mathrm{CH}$ Chiu) had performed more than 500 cases of autologous fat grafting for breast augmentation with predictable results.

We adopted 3D laser scanning in breast volume assessment in early 2015. From February 2015 to January 2016, autologous fat grafting to the breast was performed by the surgeon in 226 patients. After excluding those with previous implant augmentation, surgery for breast tumor, inadequate follow-up $(<12$ months), and more than 1 session of fat grafting to the breasts, 169 patients were enrolled in this study. Among them, 97 patients who underwent conventional fat grafting for breast augmentation were assigned to group A. The other 72 patients underwent SVF-enriched fat grafting for breast augmentation and were assigned to group B. Third-generation ultrasound-assisted liposuction (UAL) was performed to harvest the lipoaspirate in both groups. The patients' charts were retrospectively reviewed. Their demographics, complications, operation time, and clinical results were recorded and compared using SPSS software ver. 17.0 (SPSS Inc., Chicago, IL, USA), with statistical significance defined as $\mathrm{p}<0.05$.

\section{Fat grafting technique}

All procedures were performed by a single surgeon. Potential donor sites included the abdomen, flanks, hips, thighs, and calves. All patients received intravenous sedation and local tumescent anesthesia before graft harvesting. Each donor site was infiltrated with 150 to $300 \mathrm{ml}$ tumescent anesthesia $(1,000 \mathrm{ml}$ lactated Ringer's solution, $40 \mathrm{ml}$ lidocaine [2\%], and $1 \mathrm{ml}$ epinephrine $[1: 1,000]) 10$ to 15 minutes before liposuction. Thirdgeneration UAL (Ultra-Z system; Zerone Co., Ltd., Seoul, Korea) was applied with a $3.7-\mathrm{mm}$, 3-ring probe at $100 \%$ amplitude in normal mode $(10 \mathrm{~Hz})$ to the donor sites. After emulsifying the subcutaneous fat, adipose tissue was harvested with a 3- or 4-mm aspiration cannula attached to a low-pressure suction machine set to $-600 \mathrm{mmHg}$.

\section{Stromal vascular fraction-enriched fat Graft}

A portion of harvested fat $(100 \mathrm{ml})$ was mixed with $0.1 \%$ collagenase (Sigma-Aldrich, St. Louis, MO, USA) and transferred to a shaking incubator (Beauty Cell multifunctional bio-workstation; N-BIOTEK, Seoul, Korea) at $37^{\circ} \mathrm{C}(200 \mathrm{rpm})$, where the 
mixture remained for 30 minutes to dissolve the adipose tissue. The collagenase-dissolved fat was then centrifuged at $800 \mathrm{~g}$ for 5 minutes to isolate the SVF. Thereafter, the resulting cone tube showed 4 distinct layers. From top to bottom, the first layer consisted of lysed fat and oil. The second layer was the collagenase solution. The third layer contained the SVF. The bottom layer contained red blood cells (RBCs). After discarding the upper supernatant, autologous serum was used to mix with the stem cell-containing layer for neutralization at $300 \mathrm{~g}$ for 3 minutes. This process was repeated 3 times until a turbid layer between the clear supernatant of serum and the bottom RBC layer was formed. This dense, grayish layer, which appeared between the RBCs and serum, was the collection of SVF (Fig. 1). The entire procedure took 1 hour. During the isolation, the remaining aspirated fat was prepared for grafting by centrifugation at $800 \mathrm{~g}$ for 4 minutes to remove free oil and blood components. The freshly isolated SVF was then combined with the aspirated fat, which was then transferred to 10-ml BD syringes (Becton Dickinson, Franklin Lakes, NJ, USA) and connected to a 14 gauge, 15-cm, single-hole cannula for injection.

\section{Culture of adipose-derived stem cells}

To scientifically verify that stem cells were transplanted, SVF samples were further processed in an independent laboratory (Scientific Biotech Corp., Taipei, Taiwan) to isolate ADSCs following previously described methods. To assess the stem cell immunophenotype of the isolated ADSCs, the cells were harvested and characterized using flow cytometry, as described previously $[4,19]$.

\section{Volumetric analysis}

Non-contact 3D laser surface scanning (Minolta Vivid 910
3D Digitizer; Konica Minolta Inc., Tokyo, Japan) was performed with a portable device to objectively calculate the breast volume. The scanning process lasted less than 60 seconds, taking multiple views for merging. Data from these scans were merged for volumetric analysis, using Rapidform XOV2 software (INUS Technology Inc., Seoul, Korea), for each breast in all patients, by a blinded expert. To increase the intra-observer reliability, volumetric analysis for each merged 3D photograph was performed twice. The average was adopted for statistical analysis (Fig. 2).

\section{Follow-up evaluation}

Physical examination and breast ultrasonography were performed at 3, 6, and 12 months after treatment. Clinical data on all post-treatment complications were collected throughout the follow-up for all patients. Breast ultrasonography was performed routinely at follow-up visits to determine the rates of complications (fat necrosis, indurations, and calcifications). If a mass was palpable during physical examination or observed with ultrasonography, MRI for further evaluation was recommended. Patient satisfaction was assessed with an abbreviated version of the BREAST-Q, in the form of a written questionnaire administered by a nurse preoperatively and 12 months after the procedure $[20,21]$.

\section{Results}

The mean \pm standard deviation patient age was $35 \pm 8.8$ years (range, 20-56 years) in group A and 37.7 \pm 14.9 years (range, 23-53 years) in group $B$. The mean \pm standard deviation original breast volume was $97 \pm 39 \mathrm{ml}$ (range, 32-253 ml) in group A and $102 \pm 40 \mathrm{ml}$ (range, $32-193 \mathrm{ml}$ ) in group B. The mean \pm standard deviation grafted fat volume was $316 \pm 47 \mathrm{ml}$ (range, $220-400 \mathrm{ml}$ )
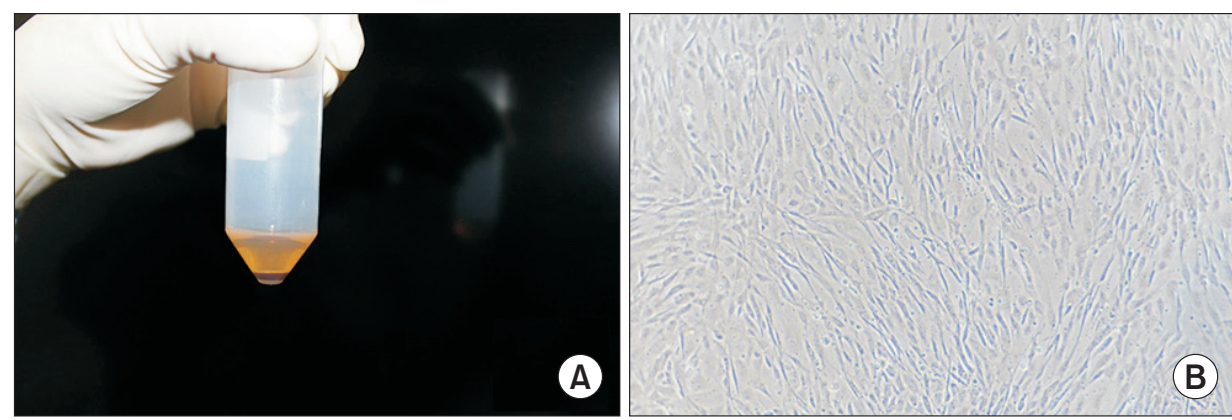

Fig. 1. Isolation of stromal vascular fraction (SVF) and culture of adipose-derived stem cell (ADSC). (A) A grayish layer containing SVF was formed between the upper layer of serum and the bottom layer of red blood cell after repeated neutralization with autologous serum. On average, $4.07 \times 10^{8}$ viable cells were yielded in SVF isolated from $100 \mathrm{ml}$ of lipoaspirate. (B) Samples of the SVF were sent to an independent laboratory outside the clinic. After 3 passages of culturing in the lab, about $6 \times 10^{6}$ stem cells were identified. The adipose-derived stem cells showed the typical elongated shape under a phase contrast light microscope $(\times 10)$. 

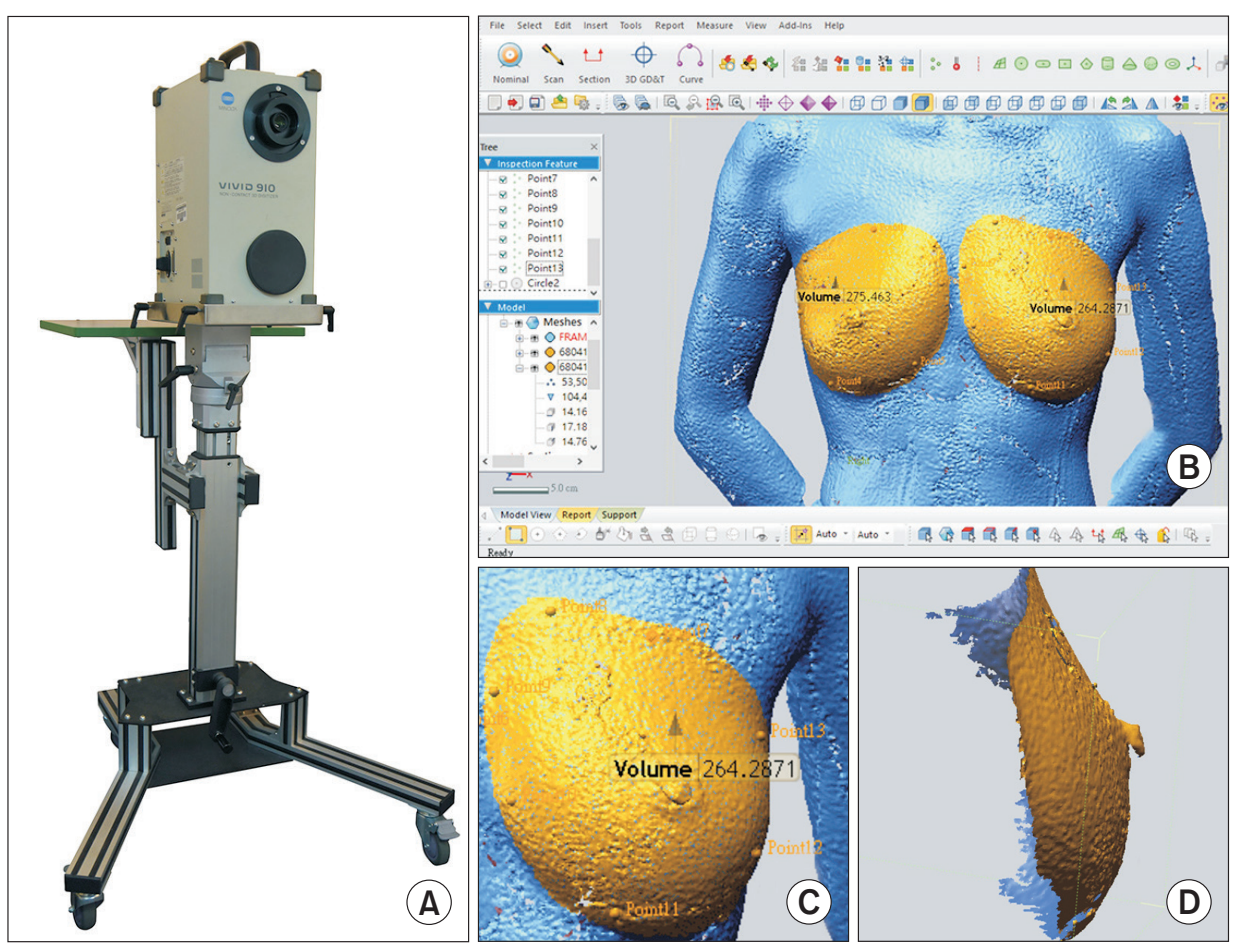

Fig. 2. Computing of breast volume using 3-dimensional (3D) laser scanning. (A) Non-contact 3D laser surface scanning (Minolta Vivid 910 3D Digitizer; Konica Minolta Inc., Tokyo, Japan) was performed with a portable device to objectively calculate the volume of the breasts. (B) A 3D photo was merged with the volume of each breast calculated using software Rapidform XOV2 (INUS Technology Inc., Seoul, Korea) on computer. (C) Close-up view of left breast with its volume calculated. (D) Breast volume was computed with the curvature of the thorax taken into consideration.

Table 1. Patients' demographic and clinical characteristics

\begin{tabular}{lccc}
\hline \multicolumn{1}{c}{ Characteristic } & Group A & Group B $^{\text {b) }}$ & p-value* $^{*}$ \\
\hline Age (yr) & $35 \pm 8.8$ & $37.7 \pm 14.9$ & 0.218 \\
\hline Preoperative BMI $\left(\mathrm{kg} / \mathrm{m}^{2}\right)$ & $18.9 \pm 1.7$ & $20.8 \pm 2.7$ & 0.006 \\
\hline Postoperative weight change $(\mathrm{kg})$ & $0.47 \pm 1.30$ & $1.06 \pm 1.94$ & 0.301 \\
\hline Total volume of suctioned fat $(\mathrm{ml})$ & $1,473 \pm 182$ & $1,760 \pm 600$ & 0.040 \\
\hline Original breast volume $(\mathrm{ml})$ & $97 \pm 39$ & $102 \pm 40$ & 0.487 \\
\hline Volume of grafted fat $(\mathrm{ml})$ & $316 \pm 47$ & $323 \pm 32$ & 0.350 \\
\hline Operation time (min) & $198 \pm 36$ & $223 \pm 51$ & 0.038 \\
\hline Complication & $5(5.2)$ & $11(15.3)$ & $<0.001$ \\
\hline
\end{tabular}

Values are presented as mean \pm SD or $\mathrm{n}(\%)$.

BMI, body mass index.

${ }^{\text {a) }}$ Patients who underwent conventional fat grafting ( $\left.n=97\right)$.

${ }^{b}$ Patients who underwent stromal vascular fraction-enriched fat grafting $(n=72)$.

*Statistical significance is considered at $\mathrm{p}<0.05$ (calculated by independent sample t-test).

in group A and $323 \pm 32 \mathrm{ml}$ (range, $240-390 \mathrm{ml}$ ) in group B. The postoperative weight change was recorded. The mean \pm standard deviation weight change was $0.47 \pm 1.30 \mathrm{~kg}$ (range, -0.2 to $2.3 \mathrm{~kg}$ ) in group A and $1.06 \pm 1.94 \mathrm{~kg}$ (range, -3.3 to $4.5 \mathrm{~kg}$ ) in group B. There were no significant differences between the 2 groups in mean age, original breast volume, grafted fat volume, and postoperative weight change. A significant lower body mass index (BMI) was observed in group A (18.9 vs. $\left.20.8 \mathrm{~kg} / \mathrm{m}^{2}, \mathrm{p}=0.006\right)$. The volume of suctioned fat in group A was significantly less than that in group $B(1,473$ vs. $1,760 \mathrm{ml}, \mathrm{p}=0.040)$. The operation time was significantly shorter in group A than in group B (198 vs. 223 minutes, $\mathrm{p}=0.038$ ). Postoperative complications included nodules, cysts, and fat necrosis. The complication rate was significantly lower in group A than in group B $(5.2 \%$ vs. $15.3 \%$, $\mathrm{p}<0.001$; Table 1).

Sequential breast volume assessments with $3 \mathrm{D}$ laser scanning revealed that the original breast volumes were $97 \mathrm{ml}$ in group A and $102 \mathrm{ml}$ in group B, with no statistically significant difference. Fourteen days after the surgery, the breast volumes increased to $502 \mathrm{ml}$ in group A and $501 \mathrm{ml}$ in group B. The breast volumes after 14 days were larger than the sum of the original breast volume and grafted volume, indicating a certain degree 
of breast swelling. At 12 months postoperatively, the breast volume was $316 \mathrm{ml}$ in group A and $332 \mathrm{ml}$ in group B, with no significant difference $(\mathrm{p}=0.258)$. The survival percentage was defined as the final breast volume minus the original breast volume, divided by the grafted fat volume. The graft survival percentage at 12 months was $69.2 \%$ in group A and $71.1 \%$ in group $\mathrm{B}$, with no significant difference $(\mathrm{p}=0.641)$. These values were close to those calculated at 3 and 6 months, suggesting that the grafted fat became stable at 3 months postoperatively (Fig. 3).

On average, $4.07 \times 10^{8}$ viable cells were yielded in SVF isolated from $100 \mathrm{ml}$ lipoaspirate. SVF samples were sent to an independent laboratory. After 3 culture passages, about $6 \times 10^{6}$ stem cells were identified. The laboratory results scientifically verified that stem cells were transplanted along with the fat graft during our surgical procedures.

\section{Discussion}

To apply SVF clinically, surgeons have to isolate a portion of the aspirated fat at the time of surgery. The SVF containing ADSCs is mixed with the fat graft in hopes of doubling the amount of stem cells, which is low in aspirated fat. In several human studies, almost half of the lipoaspirate was used for the isolation of SVF, which increased the ADSC concentration by 2 to 5 times as compared with the non-SVF fat graft $[7,11]$. As the ADSC

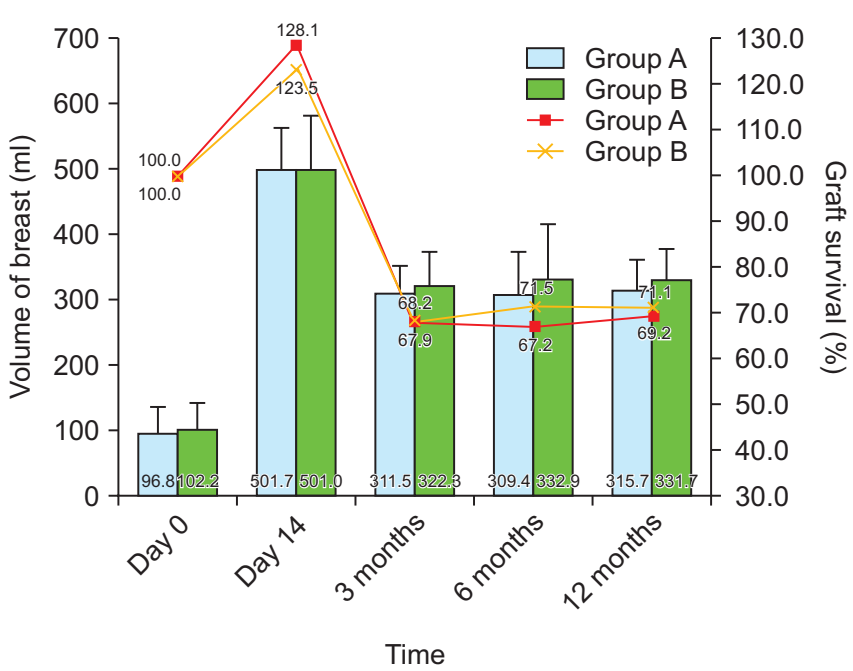

Fig. 3. Sequential changes of breast volume and percentage of graft survival. Percentage of graft survival was defined as the final breast volume minus original breast volume, divided by the volume of the grafted fat. The percentage of graft survival at 12 months did not differ in the two groups (group A, $69.2 \%$ vs. group B, $71.1 \%$; $\mathrm{p}=0.641$ ). Lines indicate percentage of graft survival. Bars indicate breast volume of each group at different time points. concentration in lipoaspirates is only half the concentration in native adipose tissue, a 2 to 5 -fold increase would only equalize the original concentration. Thereby, the improvement in fat graft survival that half of the lipoaspirate can induce remains questionable.

Our study demonstrated that isolation of SVF necessitated harvesting a larger amount of fat and a longer operation time. Unfortunately, SVF enrichment did not induce a significant increase in graft retention after 12 months of follow-up with rigorous volumetric assessment with $3 \mathrm{D}$ laser scanning. There is yet no consensus on how many cells are needed and how much fat should be used for optimum graft survival [22]. Some authors used half of the aspirated fat to isolate the SVF [2]. According to our experience and previous studies, the amount of purified fat that can be used for injection is usually one-half or two-third of the lipoaspirate amount. To prepare 540 to $600 \mathrm{ml}$ of the graft, as in our study, more than $1,000 \mathrm{ml}$ of fat should be harvested. If half of the aspirated fat were to be used for SVF isolation, surgeons would need to harvest an additional 1,000 $\mathrm{ml}$ of fat for SVF preparation according to their method, which could be problematic in thin and slim patients. In a 2015 study, $250 \mathrm{ml}$ lipoaspirate and $500 \mathrm{ml}$ liposuction fluid were used to isolate SVF, and the authors concluded that SVF from this amount of fat and fluid was not enough for optimal result [23]. In a 2013 comparative study, the authors found that the fat survival rate did not significantly differ between the CAL-enriched group (50\%) and the non-CAL group (54\%), by using 240 to $360 \mathrm{ml}$ of aspirated fat for the isolation of SVF, which is in line with our result [24].

In another study, $100 \mathrm{ml}$ of adipose tissue was reported to contain 100 million stem cells [25]. We followed a previously described protocol to isolate SVF from $100 \mathrm{ml}$ lipoaspirate. Meanwhile, fat graft was prepared from the remainder of the lipoaspirate [26]. In our study, an average of $4.07 \times 10^{8}$ viable cells were yielded in SVF isolated from $100 \mathrm{ml}$ lipoaspirate. The SVF samples were then sent to an independent laboratory. After 3 culture passages, about $6 \times 10^{6}$ stem cells were identified, which scientifically verified that stem cells were transplanted along with the fat graft during our surgical procedure. In a previous study, $1 \times 10^{4}$ SVF cells per $200 \mu \mathrm{L}$ of fat graft improved retention by approximately $20 \%$ in a xenograft model of CAL [27]. To enrich $600 \mathrm{ml}$ of fat, $3 \times 10^{7} \mathrm{SVF}$ cells $\left(1 \times 10^{7}\right.$ for $200 \mathrm{ml}, 3 \times 10^{7}$ for $600 \mathrm{ml}$ ) would be needed, according to this calculation. In our study, $4.07 \times 10^{8}$ viable cells were yielded, on average, in SVF isolated from $100 \mathrm{ml}$ lipoaspirate, which was 10 times more than that needed for the enrichment of $600 \mathrm{ml}$ fat. However, we did 
not observe any significant improvement in graft retention in our study.

The mean postoperative body weight change did not differ between the 2 groups, suggesting that graft retention was not influenced by weight change in our study. However, the preoperative BMI of group A was significantly lower than that of group B (18.9 vs. $20.8 \mathrm{~kg} / \mathrm{m}^{2}, \mathrm{p}=0.006$ ), meaning that patients in group A were thinner and more slender. These patients had a narrower chest diameter and less recipient space for fat injection. The pressure inside the breasts would be greater in group A than in group B after injecting an equivalent amount of fat, which could compromise the retention of graft [12]. Theoretically, graft retention in group A should be even lower under such circumstances, but that was not the case in the present study. We speculated that the refinement of our injection technique may have contributed to the success. The surgeon used the "solid injection method" to increase the amount of safe injection and reduce postoperative complications, in addition to the previously recommended principle of structural fat grafting [28-30]. This method was described in detail in previously published articles and was verified again in this study $[31,32]$. Over time, this method has been proven to reduce fat-grafting-related complications and enhance graft retention in the long term.

Few studies have addressed the operation time for breast augmentation with fat grafting. It was previously reported that an additional operation time of around 2 hours was needed for CAL breast augmentation [33]. In our study, an additional 30 minutes was necessary for SVF isolation if the procedure of graft preparation was performed by an expert other than the surgeon.

Postoperative complications included fat necrosis, nodules, and cyst formation. The complication rate was significantly lower in group A than in group B in our study. The mechanism behind this phenomenon was unclear. In a systematic review, the authors reported that the CAL method was associated with a higher incidence of complications [12], which was compatible with our result. They explained that a larger amount of injected fat positively correlated with a higher incidence of postoperative complications owing to the resultant local hypoxic environment. However, this presumption failed to explain the low incidence of complications in non-CAL with the injection of a similar amount of fat. In our study, the volume of transplanted fat did not significantly differ between the study groups; however, the CAL group showed higher complication rates. Accordingly, we believe that there must be causes other than hypoxia with respect to this issue; further studies are required to unravel them.

It has been clarified that fat harvested using UAL has comparable SVF counts and graft retention to those of traditional liposuction, both in human and xenograft studies [34], although the harvesting technique has an impact on cell yield and the SVF function $[35,36]$. Adipose tissue harvested using thirdgeneration UAL is viable on harvest and is a potentially suitable source for autologous fat grafts. A previous study suggested that UAL could provide an efficient method of harvesting adipose tissue without sacrificing its viability, and the authors concluded that their results were in line with those of other reports that demonstrated clinical success with third-generation UAL [37]. In the current study, UAL was performed in all patients of both groups. This was especially important when the patients seeking autologous fat grafting for breast augmentation are thin and slim. UAL has shown particular benefits in superficial liposuction and lysis of fibrous and adhesive tissues [38]. To successfully perform fat grafting to augment the breasts in underweight women, including those who had undergone liposuction, UAL is a useful technique to harvest enough amount of fat without the risk of causing skin irregularities [28,29].

According to a systematic review comparing different volumetric tools to estimate fat survival after fat grafting, MRI provides highly accurate and reproducible results. Threedimensional breast imaging systems using laser scanning or multiple stereo cameras are also accurate and reproducible for breast volume measurements [39]. MRI and 3D imaging are reliable tools for the comparative assessments of breast volume. In a review comparing various 3D techniques in breast volume analysis, the Konica Minolta Vivid 910 3D scanner was shown to be reliable and highly correlated with MRI. VECTRA 3D scanner (Canfield Scientific Inc., Fairfield, NJ, USA), on the other hand, is accurate, has low mean measurement error, and is also reliable. Although both are expensive, the former has the advantage of being portable [39,40]. For serial assessments in a short-term period, 3D laser scanning and VECTRA 3D seem to be more practical and cost-effective [17].

This study has several limitations. First, we did not perform routine mammography for all patients besides routine ultrasonography and potential MRI during postoperative followup. The postoperative complications may have been underestimated. Second, previous studies revealed that when using ADSCs through ex vivo expansion, the ADSC concentration is increased by 1,250 to 6,250 times, which considerably improves graft retention. In our research, this was not analyzed in the clinical setting. 
In conclusion, SVF-enriched fat grafting for breast augmentation was associated with a larger amount of harvested fat, a longer operation time, and a higher incidence of complications. Graft retention was not significantly increase in contrast to our expectation. Our findings do not support the use of SVF in autologous fat grafting for breast augmentation.

\section{Conflicts of interest}

The authors have nothing to disclose.

\section{References}

1. Li F, Guo W, Li K, Yu M, Tang W, Wang H, et al. Improved fat graft survival by different volume fractions of plateletrich plasma and adipose-derived stem cells. Aesthet Surg J 2015;35:319-33.

2. Ito S, Kai Y, Masuda T, Tanaka F, Matsumoto T, Kamohara $\mathrm{Y}$, et al. Long-term outcome of adipose-derived regenerative cell-enriched autologous fat transplantation for reconstruction after breast-conserving surgery for Japanese women with breast cancer. Surg Today 2017;47:1500-11.

3. Naderi N, Wilde C, Haque T, Francis W, Seifalian AM, Thornton CA, et al. Adipogenic differentiation of adipose-derived stem cells in 3-dimensional spheroid cultures (microtissue): implications for the reconstructive surgeon. J Plast Reconstr Aesthet Surg 2014;67:1726-34.

4. Zuk PA, Zhu M, Mizuno H, Huang J, Futrell JW, Katz AJ, et al. Multilineage cells from human adipose tissue: implications for cell-based therapies. Tissue Eng 2001;7:211-28.

5. Trojahn Kølle SF, Oliveri RS, Glovinski PV, Elberg JJ, FischerNielsen A, Drzewiecki KT. Importance of mesenchymal stem cells in autologous fat grafting: a systematic review of existing studies. J Plast Surg Hand Surg 2012;46:59-68.

6. Sterodimas A, de Faria J, Nicaretta B, Pitanguy I. Tissue engineering with adipose-derived stem cells (ADSCs): current and future applications. J Plast Reconstr Aesthet Surg 2010;63:1886-92.

7. Aust L, Devlin B, Foster SJ, Halvorsen YD, Hicok K, du Laney $\mathrm{T}$, et al. Yield of human adipose-derived adult stem cells from liposuction aspirates. Cytotherapy 2004;6:7-14.

8. Eto H, Kato H, Suga H, Aoi N, Doi K, Kuno S, et al. The fate of adipocytes after nonvascularized fat grafting: evidence of early death and replacement of adipocytes. Plast Reconstr Surg 2012;129:1081-92.

9. Yoshimura K, Sato K, Aoi N, Kurita M, Hirohi T, Harii K. Cell- assisted lipotransfer for cosmetic breast augmentation: supportive use of adipose-derived stem/stromal cells. Aesthetic Plast Surg 2008;32:48-55.

10. Varghese J, Griffin M, Mosahebi A, Butler P. Systematic review of patient factors affecting adipose stem cell viability and function: implications for regenerative therapy. Stem Cell Res Ther 2017;8:45.

11. Oedayrajsingh-Varma MJ, van Ham SM, Knippenberg M, Helder MN, Klein-Nulend J, Schouten TE, et al. Adipose tissue-derived mesenchymal stem cell yield and growth characteristics are affected by the tissue-harvesting procedure. Cytotherapy 2006;8:166-77.

12. Arshad Z, Karmen L, Choudhary R, Smith JA, Branford OA, Brindley DA, et al. Cell assisted lipotransfer in breast augmentation and reconstruction: a systematic review of safety, efficacy, use of patient reported outcomes and study quality. JPRAS Open 2016;10:5-20.

13. Laloze J, Varin A, Gilhodes J, Bertheuil N, Grolleau JL, Brie J, et al. Cell-assisted lipotransfer: Friend or foe in fat grafting? Systematic review and meta-analysis. J Tissue Eng Regen Med 2018;12:e1237-50.

14. Guo J, Nguyen A, Banyard DA, Fadavi D, Toranto JD, Wirth GA, et al. Stromal vascular fraction: a regenerative reality? Part 2: mechanisms of regenerative action. J Plast Reconstr Aesthet Surg 2016;69:180-8.

15. Chen YE, Gerstle TL, Liang F, Lee BT. Use of a novel laser projection grid to assess symmetry in breast surgery. Plast Reconstr Surg 2012;130:231e-3e.

16. Isogai N, Sai K, Kamiishi H, Watatani M, Inui H, Shiozaki H. Quantitative analysis of the reconstructed breast using a 3-dimensional laser light scanner. Ann Plast Surg 2006;56:237-42.

17. Rieger UM, Erba P, Wettstein R, Schumacher R, SchwenzerZimmerer K, Haug M, et al. Does abdominoplasty with liposuction of the love handles yield a shorter scar? An analysis with abdominal 3D laser scanning. Ann Plast Surg 2008;61:359-63.

18. Herold C, Ueberreiter K, Busche MN, Vogt PM. Autologous fat transplantation: volumetric tools for estimation of volume survival. A systematic review. Aesthetic Plast Surg 2013;37:380-7.

19. von Elm E, Altman DG, Egger M, Pocock SJ, Gøtzsche PC, Vandenbroucke JP; STROBE Initiative. The Strengthening the Reporting of Observational Studies in Epidemiology (STROBE) statement: guidelines for reporting observational studies. Int J Surg 2014;12:1495-9.

20. Lindroos B, Boucher S, Chase L, Kuokkanen H, Huhtala H, 
Haataja R, et al. Serum-free, xeno-free culture media maintain the proliferation rate and multipotentiality of adipose stem cells in vitro. Cytotherapy 2009;11:958-72.

21. Spear SL, Pittman T. A prospective study on lipoaugmentation of the breast. Aesthet Surg J 2014;34:400-8.

22. Cohen WA, Mundy LR, Ballard TN, Klassen A, Cano SJ, Browne J, et al. The BREAST-Q in surgical research: a review of the literature 2009-2015. J Plast Reconstr Aesthet Surg 2016; 69:149-62.

23. Zielins ER, Brett EA, Blackshear CP, Flacco J, Ransom RC, Longaker MT, et al. Purified adipose-derived stromal cells provide superior fat graft retention compared with unenriched stromal vascular fraction. Plast Reconstr Surg 2017;139: 911-4.

24. Wang L, Luo X, Lu Y, Fan ZH, Hu X. Is the resorption of grafted fat reduced in cell-assisted lipotransfer for breast augmentation? Ann Plast Surg 2015;75:128-34.

25. Peltoniemi HH, Salmi A, Miettinen S, Mannerström B, Saariniemi K, Mikkonen $\mathrm{R}$, et al. Stem cell enrichment does not warrant a higher graft survival in lipofilling of the breast: a prospective comparative study. J Plast Reconstr Aesthet Surg 2013;66:1494-503.

26. Suga H, Eto H, Aoi N, Kato H, Araki J, Doi K, et al. Adipose tissue remodeling under ischemia: death of adipocytes and activation of stem/progenitor cells. Plast Reconstr Surg 2010; 126:1911-23.

27. Estes BT, Diekman BO, Gimble JM, Guilak F. Isolation of adipose-derived stem cells and their induction to a chondrogenic phenotype. Nat Protoc 2010;5:1294-311.

28. Paik KJ, Zielins ER, Atashroo DA, Maan ZN, Duscher D, Luan A, et al. Studies in fat grafting: part V. Cell-assisted lipotransfer to enhance fat graft retention is dose dependent. Plast Reconstr Surg 2015;136:67-75.

29. Chiu $\mathrm{CH}$. Autologous fat grafting for breast augmentation in underweight women. Aesthet Surg J 2014;34:1066-82.

30. Chiu CH. Correction with autologous fat grafting for contour changes of the breasts after implant removal in Asian women.
J Plast Reconstr Aesthet Surg 2016;69:61-9.

31. Strong AL, Cederna PS, Rubin JP, Coleman SR, Levi B. The current state of fat grafting: a review of harvesting, processing, and injection techniques. Plast Reconstr Surg 2015;136: 897-912.

32. Coleman SR. Structural fat grafting: more than a permanent filler. Plast Reconstr Surg 2006;118(3 Suppl):108S-20S.

33. Chiu CH. A "solid injection method" to reduce postoperative complications in autologous fat grafting for breast augmentation. Am J Cosmet Surg 2013;30:10-5.

34. Chiu $\mathrm{CH}$. Objective evaluation of eyebrow position after autologous fat grafting to the temple and forehead. Aesthetic Plast Surg 2017;41:1342-50.

35. Fisher C, Grahovac TL, Schafer ME, Shippert RD, Marra KG, Rubin JP. Comparison of harvest and processing techniques for fat grafting and adipose stem cell isolation. Plast Reconstr Surg 2013;132:351-61.

36. Alharbi Z, Opländer C, Almakadi S, Fritz A, Vogt M, Pallua N. Conventional vs. micro-fat harvesting: how fat harvesting technique affects tissue-engineering approaches using adipose tissue-derived stem/stromal cells. J Plast Reconstr Aesthet Surg 2013;66:1271-8.

37. Chen YW, Wang JR, Liao X, Li SH, Xiao LL, Cheng B, et al. Effect of suction pressures on cell yield and functionality of the adipose-derived stromal vascular fraction. J Plast Reconstr Aesthet Surg 2017;70:257-66.

38. Schafer ME, Hicok KC, Mills DC, Cohen SR, Chao JJ. Acute adipocyte viability after third-generation ultrasound-assisted liposuction. Aesthet Surg J 2013;33:698-704.

39. Sadick NS. Overview of ultrasound-assisted liposuction, and body contouring with cellulite reduction. Semin Cutan Med Surg 2009;28:250-6.

40. Chae MP, Rozen WM, Spychal RT, Hunter-Smith DJ. Breast volumetric analysis for aesthetic planning in breast reconstruction: a literature review of techniques. Gland Surg 2016;5: 212-26. 